\title{
Quantitative Magnetic Resonance Imaging in Patients with Cirrhosis: A Cross-Sectional Study
}

Vijay P.B. Grover, ${ }^{1,2}$ Mary M.E. Crossey, ${ }^{1}$ Julie A. Fitzpatrick, ${ }^{1,2}$ Brian K. Saxby, ${ }^{3}$ Roberta Shaw, ${ }^{1}$ Adam D. Waldman, ${ }^{2}$ Marsha Y. Morgan ${ }^{4}$ and Simon D. Taylor-Robinson. ${ }^{1}$

1 Liver Unit, Division of Diabetes, Endocrinology and Metabolism, Department of Medicine, Imperial College London, London, United Kingdom.

2 Robert Steiner MRI Unit, Imaging Sciences Department, MRC Clinical Sciences Centre, Imperial College London, London, United Kingdom.

3 Centre for Ageing and Health, Newcastle University, Newcastle-upon-Tyne, United Kingdom.

4 UCL Institute for Liver \& Digestive Health, Division of Medicine, Royal Free Campus, University College London, London, United Kingdom

\section{Correspondence:}

Professor Simon D Taylor-Robinson

Professor of Translational Medicine

Department of Medicine

10th Floor QEQM Wing

St. Mary's Hospital Campus

Imperial College London

South Wharf Street

London W2 1NY

United Kingdom

Tel +44 207886 6454/6199

Fax +44 2077249369 
Cerebral magnetic resonance imaging was undertaken, at 3 Tesla field strength, employing magnetization transfer (MT) and diffusion-weighted imaging (DWI) sequences, in 26 patients with well-compensated cirrhosis, free of overt hepatic encephalopathy. Results were compared to those from 18 aged-matched healthy volunteers. Cerebral magnetization transfer ratios (MTR) were reduced in the frontal white matter, caudate, putamen and globus pallidus in patients with cirrhosis, compared to healthy controls, while the apparent diffusion coefficients ( A D C ) o n D W were significantly increased in the genu and body of the corpus callosum. An association between previous excessive alcohol consumption and both MTR and ADCs was noted, but this association was lost when controls were exercised for the severity of liver disease and psychometric impairment on multivariate analysis. Eight (31\%) of the 26 patient had impaired psychometric performance consistent with a diagnosis of minimal hepatic encephalopathy. No statistically significant difference in regional cerebral MTRs or ADCs were found in relation to neuropsychiatric status, although there was a trend towards lower MTRs in patients with impaired psychometric performance. The alterations in MTR and ADC in the patients with functionally compensated cirrhosis are compatible with theories governing the genesis of hepatic encephalopathy, including changes in astrocyte membrane permeability, with subsequent redistribution of macromolecules.

Key words: apparent diffusion coefficients; diffusion-weighted imaging; hepatic encephalopathy; magnetic resonance imaging; magnetization transfer ratios 
Hepatic encephalopathy (HE) is the term used to describe the spectrum of neuropsychiatric changes that can be observed in patients with cirrhosis. In the recent guideline published jointly by the European and American Associations for the Study of the Liver hepatic encephalopathy was defined as 'a brain dysfunction caused by liver insufficiency or portal systemic shunting' (AASLD/EASL, 2014; Vilstrup et al., 2014).

Clinically apparent or overt HE manifests as a neuropsychiatric syndrome encompassing a wide spectrum of mental and motor disorders (Weissenborn, 1998; Ferenci et al., 2002). Individuals with overt HE also show a wide spectrum of other abnormalities, including impaired psychomotor performance (Schomerus \& Hamster, 1998) and disturbed neurophysiological function (Parsons-Smith et al., 1957; Chu et al., 1997). The term minimal HE is used to describe patients with cirrhosis who are 'clinically normal', but who show abnormalities in neuropsychometric and/or neurophysiological performance (Ferenci et al., 2000).

The presence of HE, whether minimal or overt, is associated with significant impairment in the performance of complex tasks, such as driving (Bajaj et al., 2007; Schomerus et al., 1981; Wein et al., 2004); healthrelated quality of life (Groeneweg et al., 1998); earning potential (Schomerus \& Hamster 2001); safety (Roman et al., 2011); neurocognitive function post-transplantation (Sotil et al. 2009); and, ultimately, survival (Amodio et al., 1999; Bustamante et al., 1999; Stewart et al., 2007). The presence of HE also poses a substantial burden for caregivers (Bajaj et al., 2011) and a significant financial burden on health-care systems (Poordad, 2007).

Currently, there is no accepted gold standard for the diagnosis of HE (Ferenci et al., 2002). Thus, the diagnosis of overt, or clinically apparent, HE is based on a careful and detailed neuropsychiatric history and examination and exclusion of other potential causes of neuropsychiatric abnormalities; collateral evidence may be obtained from psychometric and neurophysiological testing. The diagnosis of minimal HE relies on the exclusion of symptoms and signs of overt $\mathrm{HE}$ and the finding of impaired psychomotor performance and/or abnormal neurophysiology.

Cerebral imaging should be undertaken when patients with cirrhosis first present with neuropsychiatric abnormalities in order to exclude alternative diagnoses (AASLD/EASL, 2014; Vilstrup et al., 2014) and again later if there is any suspicion of alternative neurological pathology. Less certain, however, is the role of cerebral imaging in the diagnosis of HE per se, despite the fact that numerous cerebral imaging studies, using increasingly sophisticated technologies, have been undertaken in these patients over the last two decades (Alonso et al., 2014).

Bilateral, symmetrical $\mathrm{T}_{1}$ signal hyperintensity of the globus pallidus is observed, using conventional MR techniques, in between 50 to $100 \%$ of patients with cirrhosis (Inoue et al., 1991; Pujol et al., 1996; Taylor-Robinson et al., 1995; Weissenborn et al., 1995). Signal hyperintensity has also been observed in areas adjacent to the globus pallidus in several studies (Inoue et al., 1991; Syh et al., 1991; Taylor-Robinson et al. 1995; Weissenborn et al., 1995). No significant correlations have been observed between the cerebral $\mathrm{T}_{1}$ hyperintensity and the severity of underlying liver disease in the majority of studies (Pujol et al., 1993; Rovira et al., 2001; Spahr et al., 1996; Taylor-Robinson et al., 1995; Weissenborn et al., 1995), although the pallidal hyperintensity lessens or resolves completely following liver transplantation (Pujol et al,. 1991; Pujol et al., 1993; Weissenborn et al., 1995). There is evidence of a positive relationship between cerebral 
$\mathrm{T}_{1}$ signal hyperintensity and the degree of portal systemic shunting (Inoue et al., 1991; Kulisevsky et al., 1992; Pujol et al., 1993) and the hyperintensity has been shown to increase following insertion of transjugular intrahepatic portosystemic stents (TIPS) (Krieger et al., 1997). Greater difficulties have arisen in defining the relationship between the cerebral $\mathrm{T}_{1}$ signal abnormalities and neuropsychiatric status. Nevertheless, there appears to be a consensus that cerebral $\mathrm{T}_{1}$ signal changes can be observed in patients who are neuropsychiatrically unimpaired and that the intensity of the change does not correlate with the degree of neuropsychiatric impairment (Inoue et al., 1991; Pujol et al., 1991; Thuluvath et al., 1997; TaylorRobinson et al., 1995; Weissenborn et al., 1995).

Several lines of evidence support the view that the pallidal $\mathrm{T}_{1}$ signal hyperintensity observed in patients with cirrhosis results from the deposition of manganese (Alonso et al., 2014). Thus, increases in manganese concentrations have been observed in whole blood and CSF in these patients (Katsuragi et al., 1999; Kreiger et al., 1995; Spahr et al., 1996) and in pallidal tissue obtained at post-mortem (Krieger et al., 1995; PomierLayrargues et al., 1995; Rose et al., 1999). In addition, strong collateral evidence is provided by observations in individuals with chronic manganese toxicity, resulting from industrial exposure (Nelson et al., 1993; Josephs et al., 2005) or long-term parenteral nutrition (Mirowitz et al., 1991), who show similar cerebral $\mathrm{T}_{1}$ signal abnormalities which reverse with specific therapy or cessation of long-term nutritional support (Mirowitz et al., 1991; Mirowitz \& Westrich 1992; Nelson et al., 1993; Nagatomo et al., 1999).

Magnetization transfer (MT) is a quantitative MRI technique, based on interactions and exchanges between mobile protons in a free water pool and those bound to macromolecules. By using MR sequences with and without an off-resonance saturation pulse, MT allows calculation of an index, the magnetization transfer ratio (MTR). Decreases in the MTR indicate that protons bound to the brain tissue matrix have a diminished capacity to exchange magnetization with the surrounding free water. Thus, this index provides an estimate of the extent of tissue structure disruption and affords a potential window into the macromolecular environment that is not directly visible using conventional MRI techniques (Grover et al., 2006), because it provides additional contrast in MR images and can be used to better characterize cerebral white matter.

Taylor-Robinson and colleagues (Taylor-Robinson et al., 1995) were the first to use $\mathrm{T}_{1}$-weighted MT imaging to study the brain in patients with cirrhosis. They found that while MT imaging highlighted the basal ganglia and showed a correlation between globus pallidus contrast and blood ammonia levels, MT contrast measurements did not correlate with the severity of liver dysfunction or the presence or degree of HE. Subsequently, Iwasa and colleagues reported their findings using the MTR index; they found a reduction in the ratio in the globus pallidus, which correlated with the reduction in functional hepatic reserve. (Iwasa et al., 1998) and also reported similar findings in the surrounding white matter (Iwasa et al., 1999). Similar findings of a reduction in MTR have been reported by others (Balata et al., 2003; Cordoba et al., 2001; Iwasa et al., 1999; Rovira et al., 2001; Taylor-Robinson et al., 1995), with the exception of one group (Restuccia et al., 2004), who found no difference in MTR between patients and controls, but they used a different MR sequence to the majority of other groups. These changes have been ascribed to the presence of manganese, but also of low-grade cerebral oedema.

Diffusion-weighted imaging (DWI) is a powerful MR technique, which allows tissue structure to be 
probed at the microscopic level, by quantifying the motion of water molecules. The usual image resolution capability of MR is 1-2 mm, but during the diffusion times used in DWI, typically $50 \mathrm{~ms}$, water molecules move on average $10 \mu \mathrm{m}$ (Le Bihan 2001) and interact with cell membranes, macromolecules and nerve fibres. Thus, DWI allows non-invasive, high resolution probing of brain structure, but does not interfere with the diffusion process itself. Diffusion of water molecules is an intrinsic physical process independent of the MR effect of field strength (Le Bihan et al., 2001). The two common quantitative parameters measured in DWI are the mean apparent diffusion coefficient (ADC), which is a measure of tissue water diffusivity, and the fractional anisotropy (FA), which is a measure of the overall directionality of water diffusion. The ADC is affected primarily by intracellular and extracellular volume change, extracellular tortuosity and intracellular water motion, referred to as "streaming" (Duong et al., 1998; Norris 2001). An increase in $\mathrm{ADC}$ is likely to occur when the mobility of water molecules in the extracellular space increases, for example, as a result of vasogenic or extracellular oedema (Ebisu et al., 1993; Schaefer et al., 2000; Schwartz et al., 1998).

Several cerebral DWI studies have been undertaken in patients with cirrhosis, but the results are inconsistent, primarily because the cohorts studied have been small and heterogeneous, particularly in relation to the severity of the liver disease and the degree of neuropsychiatric impairment, which was variously assessed, and the MR techniques which were not standardized ( Kale et al., 2006; Khalek et al., 2014; Lodi et al., 2004; Sugimoto et al., 2008).

Thus, currently the consensus appears to be that while studies using structural and functional cerebral imaging techniques have undoubtedly helped unravel the pathophysiology of HE, they are not thought to offer anything diagnostically (Berding et al., 2009; Grover et al., 2006). Notably, however, all the cerebral MR studies undertaken in patients with cirrhosis to date have used magnetic field strengths of 1.5T. The improved signal to noise ratio offered by $3 \mathrm{~T}$ field strengths might, at least theoretically, enhances any differences in MR characteristics not previously apparent.

The hypothesis informing this present study is that cerebral MRI, undertaken at 3 Tesla field strength, employing MT and DWI sequences will reveal pathology in the basal ganglia and other vulnerable regions of the brain in patients with cirrhosis, and particularly those with underlying HE, which is independent of other potential confounding variables such as the aetiology and severity of the underlying liver disease, alcohol misuse and current hydration status. The specific aim of this study was, therefore, to examine the relationship between changes observed in high field strength, multimodal MRI and the presence and degree of psychometric abnormalities in a group of well-characterized patients with cirrhosis and no clinical evidence of HE exercising controls for other potential confounders. MT was used to derive a quantitative measure of brain water content and membrane fluidity, and DWI to provide insight into intracellular and extracellular water changes and structural integrity.

\section{Methods}

Subjects

Patients were recruited sequentially from those attending outpatient clinics at the Imperial College 
Healthcare Trust, London. The population comprised of 26 patients (19 men: seven women; mean [range] age 51 [37-64] yr) with biopsy-proven cirrhosis. The aetiology of the liver injury was determined using clinical, laboratory, radiological and histological variables, while its severity was assessed using the Pugh modification of the Child's grading system (Pugh et al., 1971) (Table 1). All patients were clinically stable at the time of the study with Child-Pugh Grade A cirrhosis. Patients were excluded if they were under 30 or over 70 years of age; if they had evidence of clinically overt hepatic encephalopathy or had suffered an episode of major hepatic decompensation within 7 days of the assessment date; had significant cardiac, respiratory or renal failure; insulin-dependent diabetes mellitus; cerebrovascular disease; epilepsy; a history of significant head injury or other conditions likely to affect cerebral function. Patients were also excluded if they had misused alcohol or drugs in the previous three months; if their manual dexterity was impaired; if they could not speak English or obey spoken commands; or were taking psychoactive medications, including hypnotic drugs.

Healthy volunteers were recruited, by advertisement, from amongst visitors and staff at Imperial College Healthcare Trust, London. The population comprised of 18 individuals (nine men; nine women; mean age 49.0 [34-64] yr). None had a history of liver disease, significant medical co-morbidities, drank alcohol in excess of $20 \mathrm{~g}$ daily, and none took prescription or over-the-counter medications.

\section{Patient clinical and psychometric assessment}

All patients underwent detailed, clinical and laboratory assessment. The aetiology of their liver injury was determined using clinical, laboratory, radiological and histological variables. The functional severity of their liver injury was assessed using Pugh's modification of the Child's grading system (Pugh et al, 1973) and the MELD score (Malinchoc et al, 2000). Psychometric performance was assessed, by a single operator, in a quiet room with constant light level, using the validated $\mathrm{CDR} \circledast$ computer-based assessment battery (United Bioscience, Goring-on-Thames, United Kingdom). This system provides information on five domains: power of attention (PoA), continuity of attention (CoA), quality of episodic memory (QoEM), quality of working memory (QoWM) and speed of memory (SoM). The raw scores for each of these domains were compared to age-and sex-matched normative data from the CDR bank to generate $\mathrm{Z}$ scores for each individual domain and the sum of $\mathrm{Z}$ scores totaled (Table 2). Patients were classified as neuropsychometrically impaired, by CDR criteria, if the total $Z$ score was $\leq-3$ (Mardini et al. 2005). On the basis of this assessment, eight patients were classified as psychometrically impaired and hence showing evidence of minimal HE (Table 2)

\section{MR imaging}

Cerebral MRI was performed on a 3T Philips Intera ${ }^{\mathrm{TM}}$ MR system (Philips, Best, Netherlands). Standard volumetric $\mathrm{T}_{1}$-weighted sequences were performed with a three-dimensional (3D) imaging sequence: echo time (TE) $3.8 \mathrm{~ms}$, repetition time (TR) $256 \mathrm{~ms}, 1 \mathrm{NSA}, 256$ image matrix, $25 \mathrm{~cm}$ field of view (FOV) and $2.0 \mathrm{~mm}$ slice thickness. $\mathrm{T}_{2}$-weighted sequences were performed to exclude structural brain pathology, with the following sequence parameters: TE $80 \mathrm{~ms}$, TR $3000 \mathrm{~ms}$, 2 NSA, image matrix of $230,23 \mathrm{~cm}$ FOV, and $3.0 \mathrm{~mm}$ slice thickness. 
MT was obtained using a two-dimensional gradient-echo pulse sequence (TR $54.7 \mathrm{~ms}$, TE $3.75 \mathrm{~ms}$, flip angle 15 degrees, slice thickness $2 \mathrm{~mm}, 1 \mathrm{NSA}$ ) with 20 slices positioned over the basal ganglia. DWI was obtained using a standard Philips 32 direction DTI sequence (Philips, Best, The Netherlands). The sequence was constructed to obtain information from an area as small and symmetrical as possible. The voxel size that the sequence probes is $1 \times 1 \times 1.2 \mathrm{~mm}$. Data were obtained in 32 non-collinear directions of sensitisation using single-shot echo planar imaging (TR $16000 \mathrm{~ms}$, TE $51 \mathrm{~ms}$, slice thickness $2 \mathrm{~mm}, 2 \mathrm{NSA}, \mathrm{b}=1000$ $\mathrm{s} / \mathrm{mm}^{2}$ ). A SENSE factor of 2 was used to reduce image distortion. Philips PRIDETM software was used to co-register the images, correcting for motion and eddy current distortion (Philips, Best, The Netherlands). ADC and FA maps were calculated using DTI Studio ${ }^{\circledR}$ version 2.1. ADC and FA values were recorded from specific regions of interest (ROIs) in the genu, body and splenium of the corpus callosum, anterior corona radiata (ACR) and posterior corona radiata (PCR).

\section{MRI analysis}

MTR maps were calculated, using Image ${ }^{\circledR}$ version 1.32j, (www.imagej.nih.gov) with the formula $\mathrm{MTR}=100\left(\mathrm{SI}_{0}-\mathrm{SI}_{\mathrm{RF}}\right) / \mathrm{SI}_{0}$, where $\mathrm{SI}_{\mathrm{RF}}$ is the signal intensity in the image employing an off-resonance RF pulse and $\mathrm{SI}_{0}$ the signal intensity in the initial proton density image. ROIs were drawn around the (i) frontal white matter, (ii) head of caudate, (iii) putamen, (iv) globus pallidus and (v) thalamus bilaterally. The same area of ROI was used for each brain region between subjects.

The pallidal index (PI) was calculated as the ratio of the left/right averaged signal intensity in the globus pallidus, to the averaged signal intensity of frontal white matter on $\mathrm{T}_{1}$-weighted imaging multiplied by 100 (Krieger et al. 1995). Signal intensities were measured using ROIs drawn version 1.32j, (www.imagej.nih.gov).

ADC and FA maps were calculated using DTI Studio version 2.1 (www.dsi-studio.labsolver.org ). ADC and FA values were recorded from specific regions of interest (ROI) in the genu, body and splenium of the corpus callosum. These areas were chosen as they were anatomically highly conspicuous and hence, they were easily defined on this imaging sequence. A standardized area of ROI was used for the individual ROIs between different subjects.

\section{Statistical methods}

Data were tested for normality using the Shapiro-Wilk test. Between group comparisons were made with the Mann-Whitney U test. Correlations were made with the Spearman rank test. Bonferroni's correction was used to correct for multiple comparisons. Tests of significance were two-tailed. Correlation coefficients between regional MTRs on MT imaging, or ADC and FA on DWI and individual psychometric domains measured by the CDR® system were calculated using Spearman's rank test. Univariate linear regression was used to determine if age, sex, aetiology and severity of liver disease, history of alcohol misuse, individual laboratory variables including liver function tests and serum sodium concentrations and the presence of neuropsychometric impairment were associated with observed changes in the MTR and ADC. Statistical analyses were performed using SPSS version 16 (SPSS Inc., USA). 


\section{Ethics}

Ethical approval was obtained from the Hammersmith, Queen Charlotte's \& Chelsea Research Ethics Committee (ref 04/Q0406/161) and the study was compliant with the principles outlined in the 1975 Declaration of Helsinki on Human Rights. Local Research Governance approval and indemnity, was provided by Imperial College London. All subjects provided written informed consent. 


\section{Results}

No structural cerebral abnormalities were observed, on standard $\mathrm{T}_{2}$-weighted MRI in any of the patients or control subjects. There were no difference in brain volumes between the patients and the age-matched healthy volunteers on $\mathrm{T}_{1}$-weighted volumetric imaging.

\section{Magnetization transfer ratios}

MTRs were significantly decreased in the frontal white matter, caudate, putamen and globus pallidus in the patients with cirrhosis (Table 3) even after correction for multiple comparisons. The greatest reductions in MTR were found in the frontal white matter (4\%) (Figure 1) and the globus pallidus $(5.8 \%)$ (Figure 2).

\section{Diffusion-weighted imaging}

The ADC was measured in nine brain regions. A significant increase in ADC was found in the genu and body of the corpus callosum in the patients with cirrhosis compared to controls (Table 4), even after correction for multiple comparisons. There was no significant difference in fractional anisotropy (FA) between patients and controls.

\section{MRI associations: patient populations and degree of psychometric impairment}

There were no statistically significant differences in MTR in any of the cerebral areas studied between the unimpaired patients and those classified as having minimal HE. However there was a non-significant between-group trend of reducing MTR between unimpaired patients and those with minimal HE, particularly in the frontal white matter and the globus pallidus (Table 3).

There was an association on univariate analysis between the presence of minimal HE and a reduction in regional cerebral MTRs, but this association was lost on multivariate analysis after correction for the severity of liver disease and a history of alcohol misuse. No association was found between the MT imaging data and the individual psychometric domains measured by the CDR® system.

ADC values tended to be higher in the genu and body of the corpus callosum in the unimpaired patients with cirrhosis, but the differences between values in the unimpaired patients and those with minimal hepatic encephalopathy were not statistically significant. No association was found between the diffusion-weighted imaging data and the individual psychometric domains measured by the CDR® system.

\section{MRI: patient population by aetiology of liver injury}

Patients' whose liver disease was caused by a combination of chronic HCV infection and alcohol misuse were excluded from the by aetiology analyses. There were no significant differences in regional brain MTRs between patients with alcohol-related cirrhosis and those with non-alcohol related cirrhosis considered together. However, there was a trend towards a lower MTR in those with alcohol-related disease. 
There was no significant difference in MTRs between neuropsychometrically impaired and unimpaired patients within the alcohol-related cirrhosis and non-alcohol-related cirrhosis cohorts. There was no significant difference in ADC or FA, between impaired and unimpaired patients, within the alcoholrelated cirrhosis and non-alcohol-related cirrhosis cohorts.

In univariate analysis alcohol misuse was the only variable associated with a reduction in MTR in the frontal white matter, head of caudate, putamen and globus pallidus and an increase in ADC in the genu and body of the corpus callosum.. However, after adjusting for the effects of the severity of liver disease and psychometric impairment in multivariate analysis these associations were not sustained. None of the other variables tested was associated with the observed changes in MTR and ADC. 


\section{Discussion}

The main findings in the present study were that mean MTRs were reduced in the frontal white matter and basal ganglia structures in the brains of patients with cirrhosis, while mean ADCs were increased in areas of the corpus callosum.

There are several possible explanations for the reduction observed in MTR including damage to myelin or to the axonal membrane (Lexa et al. 1994; van Waesberghe et al. 1999), deposition of paramagnetic substances (Iwasa et al. 1998) and low-grade cellular/cerebral oedema (Balata et al. 2003; Cordoba et al. 2001). Damage to myelin or the axonal membranes is an unlikely explanation as (i) cerebral proton magnetic resonance spectroscopy studies ( ${ }^{1} \mathrm{H}$ MRS) studies in patients with cirrhosis have invariable shown no significant changes in the signal for n-acetyl-aspartate, a marker of neuronal integrity; and (ii) FA was unchanged, indicating structural integrity (Taylor-Robinson et al., 1996).

Iwasa and colleagues demonstrated a strong inverse relationship between the manganese concentration in manganese chloride phantoms and the MTR, thus supporting the hypothesis that manganese deposition in the brain may account for the observed reduction in MTRs. However, they found no association between the whole blood manganese levels and MTRs in the patients studied (Iwasa et al. 1998). Post-mortem studies have confirmed an association between pre-mortem $\mathrm{T}_{1}$ hyperintensity and elevated post-mortem levels of manganese in the basal ganglia in patients who died with chronic liver disease (Krieger et al. 1995; Maeda et al. 1997). Given that the MT sequence was $\mathrm{T}_{1}$-weighted, this would also be supportive of an association between MTRs and manganese deposition in the context of cirrhosis. The observation that the reduction in MTR rapidly improves after liver transplantation (Cordoba et al. 2001) may be supportive of the manganese deposition hypothesis, as cholestasis, which is also associated with pallidal manganese deposition, improves post-transplantation. However, the observation that in occupational manganese exposure the resolution in cerebral pallidal $\mathrm{T}_{1}$ hyperintensity is much slower (Josephs et al. 2005) suggests that this is a more complex issue.

Low grade cerebral/cellular oedema is often cited as the explanation for reduced MTRs in patients with cirrhosis (Balata et al. 2003; Cordoba et al. 2001; Miese et al. 2006; Poveda et al., 2010; Rovira et al. 2001). This is supported by the finding of reduced intracellular levels of the cerebral osmolyte myo-inositol (mI), reported in ${ }^{1} \mathrm{H}$ MRS studies (Häussinger et al. 2000). This may result from expulsion of mI from cells, in order to try to compensate for cellular oedema.

In the present study, mean ADCs were measured in a total of nine white and grey matter structures. There was a statistically significantly increase in the mean ADCs in patients with cirrhosis compared to controls in two of these regions, although the ADC was higher in all of the nine regions studied. The two compartment model for the interpretation of diffusion suggests that the extracellular fluid, with relatively fast and unhindered motion of water molecules, is the main component of the overall diffusivity whereas the intracellular compartment, with its cellular structures, is characterised by restricted motion of protons and hence contributes less to overall diffusivity (Norris 2001). Thus, a finding of elevated ADCs would usually be attributed to an increase in extracellular fluid. However, it has been suggested that if the increase 
in ADC is accompanied by a reduction in MTR, as in the present study, this could reflect minimal cellular oedema with an increase of membrane permeability and increased intracellular diffusivity, as well as changes in the viscosity of the cytoplasm (Lodi et al. 2004). Microscopically the most striking feature observed in the brains of individuals dying of chronic liver failure is proliferation of the astrocytes with development of enlarged nuclei, prominent nucleoli, margination of chromatin and accumulation of glycogen - changes referred to as Alzheimer type II astrocytosis (Butterworth, 2002). These changes are found particularly in the cerebral cortex, basal ganglia and cerebellum. In addition, the expression of glial fibrillary acid protein (GFAP), which is a major contributor to the filamentous structures within astrocytes (Eng et al. 2000), is reduced in astrocytes in the basal ganglia and cerebral cortex (Sobel et al. 1981). Thus, the astrocytes in HE demonstrate cytoplasmic change and as they occupy one-third of the cerebral volume, this may explain the observed reduction in mean MTRs and the increase in mean ADC observed in this patient population.

It has been suggested that some of the MR-measurable changes observed in patients with cirrhosis might be attenuated in those with a history of alcohol misuse. Thus, Miese et al. (2006) reported a significant decrease in the MTR of the thalamus, globus pallidus, putamen, and white matter in patients with nonalcohol-related cirrhosis which negatively correlated with the severity of HE. However, in patients with alcohol-related cirrhosis the MTR was significantly decreased in all regions assessed, but showed no correlation with the severity of HE. Likewise, in patients with non-alcohol-related cirrhosis, the ADC in the occipital white matter was not significantly altered, but showed a tendency toward increased values in the thalamus and in normal-appearing white matter in those with overt HE, whereas there were no significant differences in ADC in any of the examined regions in patients with alcohol-related cirrhosis. The authors' speculated that the discrepancy between the MRI findings in the patients with alcohol-related and nonalcohol-related cirrhosis might reflect the presence of alcohol-related microstructural change or alcoholrelated changes in membrane lipid composition. Thus, alcohol-tolerant membranes in the brains of patients with alcohol-related cirrhosis might exhibit a systematically different MT ability than those of non-alcoholic patients with cirrhosis.

In the present study, there was a non-significant trend towards a greater reduction in MTRs in patients with alcohol-related cirrhosis and minimal HE. Alcohol misuse was an independent predictor of the reduction in MTR in the frontal white matter, head of caudate, putamen and globus pallidus; and of the increase in ADC in the genu and body of the corpus callosum. However, the significance of these associations was lost after adjusting for the effects of the presence of liver disease and psychometric impairment. There was no statistically significant difference in mean MTRs in patients in relation to the presence of psychometric impairment contrasting with the findings of others. (Cordoba et al. 2001; Restuccia et al. 2004; Rovira et al. 2001). However, this may be a reflection of the small number of patients with minimal HE within the group, supported by the fact that there was a tendency for MTRs to be lower in the patients with impaired psychometric performance. This could not have been addressed at enrolment, as the study design was to recruit unselected patients who met inclusion criteria without biasing interpretation of the MR findings by knowledge of their psychometric status. No really meaningful comparisons of the relationship between MR-measured variables and psychometric status in subgroups by aetiology could 
be made as the subgroups numbers were very small

In conclusion, this study has demonstrated the utility of the MT and DWI sequences to detect differences in cerebral MTRs and ADCs in patients with cirrhosis and provides further insights into the pathophysiology of HE, in particular the potential effects of changes in astrocyte membrane permeability, with subsequent redistribution of macromolecules. However, future studies which include concurrent functional MRI sequences (Ahluwalia et al., 2014) may also shed further light on the meaning and context of the changes observed with MTR and DWI. 


\section{Acknowledgements}

All authors acknowledge the support of the National Institute for Health Research Biomedical Research Centre at Imperial College London for infrastructure support. VPBG was supported by grants from the Royal College of Physicians of London, the University of London and the Trustees of St Mary's Hospital, Paddington. MMEC is supported by a Fellowship from the Sir Halley Stewart Trust (Cambridge, United Kingdom). MMEC and SDT-R hold grants from the United Kingdom Medical Research Council, which provided running costs and some infrastructure support for the study. 


\section{References}

Ahluwalia V, Wade JB, Heuman DM, Hammeke TA, Sanyal AJ, Sterling RK, Stravitz TR, Luketic V, Siddiqui MS, Puri P, Fuchs M, Lennon MJ, Kraft KA, Gilles H, White MB, Noble NA, Bajaj JS (2014) Enhancement of functional connectivity, working memory and inhibitory control on multi-modal brain MR imaging with Rifaximin in Cirrhosis: Implications for the gut-liver-brain axis. Metab Brain Dis 29(3):1017-1025.

Alonso J, Cordoba J, Rovira A. (2014) Brain magnetic resonance in hepatic encephalopathy Semin Ultrasound CT MRI 35:136-152

Amodio P, Del Piccolo F, Marchetti P, Angeli P, Iemmolo R, Caregaro L, Merkel C, Gerunda G, Gatta A (1999) Clinical features and survival of cirrhotic patients with subclinical cognitive alterations detected by the number connection test and computerized psychometric tests. Hepatology 29(6): 1662-1667.

American Association for the Study of Liver: European Association for the Study of the Liver. Hepatic encephalopathy in chronic liver disease (2014) 2014 Practice Guideline by the European Association for the Study of the Liver and the American Association for the Study of Liver Diseases. J Hepatol 61(3):642-659.

Bajaj JS, Hafeezullah M, Hoffmann RG, Saeian K (2007) Minimal hepatic encephalopathy: a vehicle for accidents and traffic violations. Am J Gastroenterol 102(9): 1903-1909.

Bajaj JS, Wade JB, Gibson DP, Heuman DM, Thacker LR, Sterling RK, Stravitz RT, Luketic V, Fuchs M, White MB, Bell DE, Gilles H, Morton K, Noble N, Puri P, Sanyal AJ (2011) The multi-dimentional burden of cirrhosis and hepatic encephalopathy on patients and caregivers. Am J Gastroenterol 106(9): 1646-1653.

Balata S, Olde Damink SW, Ferguson K, Marshall I, Hayes PC, Deutz NE, Williams R, Wardlaw J, Jalan R (2003) Induced hyperammonemia alters neuropsychology, brain MR spectroscopy and magnetization transfer in cirrhosis. Hepatology 37(4): 931-939.

Berding G, Banati RB, Buchert R Chierichetti F, Grover VP, Kato A, Keiding S, Taylor-Robinson SD; International Society for Hepatic Encephalopathy and Nitrogen Metabolism (ISHEN) (2009) Radiotracer imaging studies in hepatic encephalopathy: ISHEN practice guidelines. Liver Int; 29(5): 621-628.

Bustamante J, Rimola A, Ventura Pj, Navasa M, Cirera I, Reggiardo V, Rodés J (1999) Prognostic significance of hepatic encephalopathy in patients with cirrhosis. J Hepatol 30(5):890-895.

Butterworth RF (2002) Pathophysiology of hepatic encephalopathy: a new look at ammonia. Metab Brain Dis 17(4): 221-227.

Chu NS, Yang SS, Liaw YF (1997) Evoked potentials in liver diseases. J Gastroenterol Hepatol 12 (9-10): 
S288-293.

Córdoba J, Alonso J, Rovira A, Jacas C, Sanpedro F, Castells L, Vargas V, Margarit C, Kulisewsky J, Esteban R, Guardia J (2001) The development of low-grade cerebral edema in cirrhosis is supported by the evolution of ${ }^{1} \mathrm{H}$-magnetic resonance abnormalities after liver transplantation. J Hepatol 35(5): 598-604.

Duong TQ, Ackerman JJ, Ying HS, Neil JJ (1998) Evaluation of extra- and intracellular apparent diffusion in normal and globally ischemic rat brain via 19F NMR. Magn Reson Med 40(1): 1-13.

Ebisu T, Naruse S, Horikawa Y, Ueda S, Tanaka C, Uto M, Umeda M, Higuchi T (1993) Discrimination between different types of white matter edema with diffusion-weighted MR imaging. J Magn Reson Imaging 3(6): 863-868.

Eng LF, Ghirnikar RS, Lee YL (2000) Glial fibrillary acidic protein: GFAP-thirty-one years (1969-2000). Neurochem Res 25(9-10): 1439-1451.

Ferenci P, Dragosics B, Grunt W, Hentschel E, Königsrainer A, Petritsch W, Winkler H, Munda W. (2000) Work capacity evaluation in gastrointestinal and liver diseases: Report of the $10^{\text {th }}$ Continuing Education Course of the Austrian Society of Gastroenterology and Hepatology in Alpbach, 2000. Z. Gastroenterol 38(11): XIX-XXIV.

Ferenci P, Lockwood AH, Mullen K, Tarter R, Weissenborn K, Blei AT (2002) Hepatic encephalopathy-Definition, nomenclature, diagnosis, and quantification: Final report of the Working Party at the 11th World Congresses of Gastroenterology, Vienna, 1998. Hepatology 35(3): 716-721.

Groeneweg M, Quero JC, De BI, Hartmann IJ, Essink-bot ML, Hop WC, Schalm SW (1998) Subclinical hepatic encephalopathy impairs daily functioning. Hepatology 28(1): 45-49.

Grover VPB, Dresner MA, Forton DM, Counsell S, Larkman DJ, Patel N, Thomas HC, Taylor-Robinson SD (2006) Current and future applications of magnetic resonance imaging and spectroscopy of the brain in hepatic encephalopathy. World J Gastroenterol 12(19): 2969-2978.

Häussinger D, Kircheis G, Fischer R, Schliess F, vom Dahl S (2000) Hepatic encephalopathy in chronic liver disease: a clinical manifestation of astrocyte swelling and low-grade cerebral edema? J Hepatol 32(6): 1035-1038.

Inoue E, Hori S, Narumi Y, Fujita M, Kuriyama K, Kadota T, Kuroda C (1991) Portal-systemic encephalopathy: presence of basal ganglia lesions with high signal intensity on MR images. Radiology 179(2): 551-555.

Iwasa M, Kinosada Y, Nakatsuka A, Watanabe S, Adachi Y (1999) Magnetization transfer contrast of various regions of the brain in liver cirrhosis. AJNR Am J Neuroradiol 20(4): 652-654.

Iwasa M, Kinosada Y, Watanabe S, Furuta M, Yuda H, Kawamura N, Nakayabu M, Esaki A, Sato T, 
Deguchi T, Nakatsuka A, Adachi Y (1998) Hepatic cirrhosis: magnetization transfer contrast in the globus pallidus. Neuroradiology 40(3): 145-149.

Josephs KA, Ahlskog JE, Klos KJ, Kumar N, Fealey RD, Trenerry MR, Cowl CT (2005) Neurologic manifestations in welders with pallidal MRI T1 hyperintensity. Neurology 64(12): 2033-2039.

Kale RA, Gupta RK, Saraswat VA, Hasan KM, Trivedi R, Mishra AM, Ranjan P, Pandey CM, Narayana PA (2006) Demonstration of interstitial cerebral edema with diffusion tensor MR imaging in type C hepatic encephalopathy. Hepatology 43(4): 698-706.

Katsuragi T, Iseki E, Kosaka K, Koyano S, Iwabuchi K (1999) Cerebrospinal fluid manganese concentrations in patients with symmetric pallidal hyperintensities on T1-weighted MRI. J Neurol Neurosurg Psychiatry 66(4): 551-552.

Khalek AA, Razek A, Abdalla A, Ezzat A, Megahed A, Barakat T. (2014) Minimal hepatic encephalopathy in children with liver cirrhosis: diffusion-weighted MR imaging and proton MR spectroscopy of the brain. Neuroradiology 56 (7):885-891

Krieger D, Krieger S, Jansen O, Gass P, Theilmann L, Lichtnecker H (1995) Manganese and chronic hepatic encephalopathy. Lancet 346(8970): 270-274.

Krieger S, Jauss M, Jansen O, Stiehl A, Sauer P, Geissler M, Theilmann L, Krieger D (1997) MRI findings in chronic hepatic encephalopathy depend on portosystemic shunt: results of a controlled prospective clinical investigation. J Hepatol 27(1): 121-126.

Kulisevsky J, Pujol J, Balanzó J, Junqué C, Deus J, Capdevilla A, Villanueva C (1992) Pallidal hyperintensity on magnetic resonance imaging in cirrhotic patients: clinical correlations. Hepatology 16(6): 1382-1388.

Le Bihan D (2007) The 'wet mind': water and functional neuroimaging. Phys Med Biol 52(7): R57-R90.

Le Bihan D, Mangin JF, Poupon C, Clark CA, Pappata S, Molko N, Chabriat H (2001) Diffusion tensor imaging: concepts and applications. J Magn Reson Imaging 13(4): 534-546.

Lexa FJ, Grossman RI, Rosenquist AC ( 1994 ) Dyke Award paper. MR of Wallerian degeneration in the feline visual system: characterization by magnetization transfer rate with histopathologic correlation. AJNR Am J Neuroradiol 15(2): 201-212.

Lodi R, Tonon C, Stracciari A, Weiger M, Camaggi V, Iotti S, Donati G, Guarino M, Bolondi L, Barbiroli B (2004) Diffusion MRI shows increased water apparent diffusion coefficient in the brains of cirrhotics. Neurology 62(5): 762-766. 
Maeda H, Sato M, Yoshikawa A, Kimura M, Sonomura T, Terada M, Kishi K (1997) Brain MR imaging in patients with hepatic cirrhosis: relationship between high intensity signal in basal ganglia on T1weighted images and elemental concentrations in brain. Neuroradiology 39(8): 546-550.

Malinchoc M, Kamath PS, Gordon FD, Peinie CJ, Rank J, ter Borg PC (2000) A model to predict poor survival in patients undergoing transjugular intrahepatic portosystemic shunts. Hepatology 31(4) 864871.

Mardini H, Saxby BK, Record CO (2008) Computerized psychometric testing in minimal encephalopathy and modulation by nitrogen challenge and liver transplant. Gastroenterology 135(5): 1582-1590.

Miese F, Kircheis G, Wittsack HJ, Wenserski F, Hemker J, Modder U, Häussinger D, Cohnen, M (2006) ${ }^{1} \mathrm{H}-\mathrm{MR}$ spectroscopy, magnetization transfer, and diffusion-weighted imaging in alcoholic and nonalcoholic patients with cirrhosis with hepatic encephalopathy. AJNR Am J Neuroradiol 27(5): 1019-1026.

Mirowitz SA, Westrich TJ (1992) Basal ganglial signal intensity alterations: reversal after discontinuation of parenteral manganese administration. Radiology 185(2): 535-536.

Mirowitz SA, Westrich TJ, Hirsch J D (1991) Hyperintense basal ganglia on T1-weighted MR images in patients receiving parenteral nutrition. Radiology 181(1): 117-120.

Nagatomo S, Umehara F, Hanada K, Nobuhara Y, Takenaga S, Arimura K, Osame M (1999) Manganese intoxication during total parenteral nutrition: report of two cases and review of the literature. J Neurol Sci 162(1): 102-105.

Nelson K, Golnick J, Kórn T, Angle C (1993) Manganese encephalopathy: utility of early magnetic resonance imaging. Br J Ind Med 50(6): 510-513.

Norris DG (2001) The effects of microscopic tissue parameters on the diffusion-weighted magnetic resonance imaging experiment. NMR Biomed 14(2): 77-93.

Parsons-Smith, B. G., Summerskill, W. H., Dawson, A. M., \& Sherlock, S. (1957) The electroencephalograph in liver disease. Lancet 273 (7001): 867-871.

Pomier-Layrargues G, Spahr L, Butterworth RF (1995) Increased manganese concentrations in pallidum of cirrhotic patients. Lancet 345(8951): 735.

Poordad FF (2007) Review of the burden of hepatic encephalopathy. Aliment Pharmacol Ther 25 (Suppl 1): $3-9$. 
Poveda MJ, Bernabeu A, Concepción L, Roa E, de Madaria E, Zapater P, Pérez-Mateo M, Jover R. (2014) Brain edema dynamics in patients with overt hepatic encephalopathy: A magnetic resonance imaging study. NeuroImage 52 (6): 481-487

Pugh, R. N., Murray-Lyon, I. M., Dawson, J. L., Pietroni, M. C., \& Williams, R. (1973), Transection of the oesophagus for bleeding oesophageal varices. Br J Surg, 60 (8): 646-649.

Pujol A, Graus F, Peri J, Mercader JM, Rimola A ( 1991) Hyperintensity of the globus pallidus on $\mathrm{T}_{1}$ weighted and inversion-recovery MRI: a possible marker of advanced liver disease. Neurology 41(9): $1526-527$

Pujol A, Pujol J, Graus F, Rimola A, Peri J, Mercader JM, Garcia-Pagan JC, Bosch J, Rodes J, Tolosa E (1993) Hyperintense globus pallidus on $\mathrm{T}_{1}$-weighted MRI in cirrhotic patients is associated with severity of liver failure. Neurology 43(1): 65-69.

Pujol J, Kulisevsky J, Moreno A, Deus J, Alonso J, Balanzo J, Marti-Vilalta JL, Capdevila A (1996) Neurospectroscopic alterations and globus pallidus hyperintensity as related magnetic resonance markers of reversible hepatic encephalopathy. Neurology 47(6): 1526-1530.

Rose C, Butterworth RF, Zayed J, Normandin L, Todd K, Michalak A, Spahr L, Huet PM, PomierLayrargues G (1999) Manganese deposition in basal ganglia structures results from both portal-systemic shunting and liver dysfunction. Gastroenterology 117(3): 640-644.

Roman E, Córdoba J, Torrens M, Torras X, Villanueva C, Vargas V, Guarner C, Soriano G (2011) Minimal hepatic encephalopathy is associated with falls. Am J Gastroenterol 106(3): 476-482.

Rovira A, Grive E, Pedraza S, Rovira A, Alonso J (2001) Magnetization transfer ratio values and proton MR spectroscopy of normal-appearing cerebral white matter in patients with liver cirrhosis. AJNR Am J Neuroradiol 22(6): 1137-1142.

Syh HW, Chu WK, Mar N, McConnell JR (1991) An image analysis on MR imaging of the brain for hepatic encephalopathy. Biomed Sci Instrum 27 (6): 29-33.

Schaefer PW, Grant PE, Gonzalez RG (2000) Diffusion- weighted MR imaging of the brain. Radiology 217(2): 331-345.

Schomerus H, Hamster W (1998) Neuropsychological aspects of portal-systemic encephalopathy. Metab Brain Dis 13(4): 361-377.

Schomerus H, Hamster W (2001) Quality of life in cirrhotics with minimal hepatic encephalopathy. Metab Brain Dis 16(1-2): 37-41.

Schomerus H, Hamster W, Blunck H, Reinhard U, Mayer K, Dolle W (1981) Latent portasystemic encephalopathy. I. Nature of cerebral functional defects and their effect on fitness to drive. Dig Dis Sci 
26: 622-630.

Schwartz RB, Mulkern RV, Gudbjartsson H, Jolesz F (1998) Diffusion-weighted MR imaging in hypertensive encephalopathy: clues to pathogenesis. AJNR Am J Neuroradiol 19(5): 859-862.

Sotil E U, Gottstein J, Ayala E, Randolph C, Blei AT (2009) Impact of preoperative overt hepatic encephalopathy on neurocognitive function after liver transplantation. Liver Transpl 15(2): 184-192.

Spahr L, Butterworth RF, Fontaine S, Bui L, Therrien G, Milette PC, Lebrun LH, Zayed J, Leblanc A, Pomier-Layrargues G (1996) Increased blood manganese in cirrhotic patients: relationship to pallidal magnetic resonance signal hyperintensity and neurological symptoms. Hepatology 24(5): 1116-1120.

Stewart CA, Malinchoc M, Kim WR, Kamath P S (2007) Hepatic encephalopathy as a predictor of survival in patients with end-stage liver disease. Liver Transpl 13(10): 1366-1371.

Sugimoto R, Iwasa M, Maeda M, Urawa N, Tanaka H, Fujita N, Kobayashi Y, Takeda K, Kaito M, Takei Y (2008) Value of the apparent diffusion coefficient for quantification of low-grade hepatic encephalopathy. Am J Gastroenterol 103(6): 1413-1420.

Taylor-Robinson S, Oatridge A, Hajnal J, Burroughs A, McIntyre N, deSouza N (1995) MR imaging of the basal ganglia in chronic liver disease: correlation of $\mathrm{T}_{1}$-weighted and magnetization transfer contrast measurements with liver dysfunction and neuropsychiatric status. Metab Brain Dis 10(3): 175-188.

Taylor-Robinson SD, Sargentoni J, Oatridge A, Bryant DJ, Hajnal JV, Marcus CD, Seery JP, Hodgson HJ, deSouza NM (1996) MR imaging and spectroscopy of the basal ganglia in chronic liver disease: correlation of $\mathrm{T}_{1}$-weighted contrast measurements with abnormalities in proton and phosphorus-31 MR spectra. Metab Brain Dis 11(3): 249-268.

Thuluvath PJ, Edwin D, Yue NC, de Villiers C, Hochman S, Klein A (1995) increased signals seen in globus pallidus in T1-weighted magnetic resonance imaging in cirrhotics are not suestive of chronic hepatic encephalopathy. Hepatology 21(2): 440-442.

Van Buchem MA Tofts PS (2000) Magnetization transfer imaging. Neuroimaging Clin N Am 10(4): 771778.

van Waesberghe JH, Kamphorst W, De Groot CJ, van Walderveen MA, Castelijns JA, Ravid R, Lycklama à Nijeholt GJ, van de Valk P, Polman CH, Thompson AJ, Barkhof F (1999) Axonal loss in multiple sclerosis lesions: magnetic resonance imaging insights into substrates of disability. Ann Neurol 46(5): 747-754.

Vilstrup H, Amodio P, Bajaj J, Cordoba J, Ferenci P, Mullen KD, Weissenborn K, Wong P (2014) Hepatic encephalopathy in chronic liver disease: 2014 Practice Guideline by the American Association for the Study of Liver Diseases and the European Association for the Study of the Liver. Hepatology 60(2):715735 . 
Wein C, Koch H, Popp B, Oeher G, Schauder P (2004) Minimal hepatic encephalopathy impairs fitness to drive. Hepatology 39(3): 739-745.

Weissenborn K (1998) Diagnosis of encephalopathy. Digestion 59 (suppl 2): 22-24

Weissenborn K, Ehrenheim C, Hori A, Kubicka S, Manns MP (1995) Pallidal lesions in patients with liver cirrhosis: clinical and MRI evaluation. Metab Brain Dis 10(3): 219-231. 


\section{Figure legends}

Figure 1 Box plot of cerebral magnetization transfer ratio (MTR) in the frontal white matter in patients with cirrhosis $(n=24)$ and age-matched healthy controls $(n=15)$ (median and interquartile range values)

Figure 2: Box plot of cerebral magnetization transfer ratio (MTR) in the globus pallidus in patients with cirrhosis ( $\mathrm{n}=24)$ and age-matched healthy controls $(\mathrm{n}=15)$ (median and range interquartile values) 
Table 1 Characteristics of the 26 patients with cirrhosis, free of overt hepatic encephalopathy, undergoing cerebral MRI

\begin{tabular}{|c|c|c|c|}
\hline Study number & Sex & $\begin{array}{l}\text { Age } \\
(\mathbf{y r})\end{array}$ & Aetiology of cirrhosis \\
\hline 1 & $\mathrm{~F}$ & 52 & Alcohol \\
\hline 2 & $\mathrm{~F}$ & 51 & Hepatitis $C^{*}$ \\
\hline 3 & $\mathrm{~F}$ & 47 & Autoimmune hepatitis \\
\hline 4 & $\mathrm{~F}$ & 56 & Hepatitis C \\
\hline 5 & M & 48 & Alcohol + hepatitis $C^{*}$ \\
\hline 6 & M & 49 & Alcohol \\
\hline 7 & $\mathrm{~F}$ & 64 & Autoimmune hepatitis \\
\hline 8 & M & 64 & Alcohol \\
\hline 9 & M & 63 & Hepatitis C \\
\hline 10 & M & 61 & Alcohol \\
\hline 11 & M & 57 & Cryptogenic \\
\hline 12 & M & 51 & Alcohol + Hepatitis C \\
\hline 13 & M & 48 & Hepatitis C \\
\hline 14 & M & 47 & Primary biliary cirrhosis \\
\hline 15 & M & 46 & Alcohol \\
\hline 16 & M & 38 & Haemochromatosis \\
\hline 17 & M & 56 & Alcohol + hepatitis $C^{*}$ \\
\hline 18 & M & 50 & Hepatitis $C^{*}$ \\
\hline 19 & M & 39 & Hepatitis $C^{*}$ \\
\hline 20 & M & 44 & Alcohol \\
\hline 21 & M & 37 & Hepatitis B \\
\hline 22 & M & 46 & Alcohol + hepatitis $C^{*}$ \\
\hline 23 & M & 45 & Haemochromatosis \\
\hline 24 & $\mathrm{~F}$ & 62 & Primary biliary cirrhosis \\
\hline 25 & $\mathrm{~F}$ & 45 & Alcohol \\
\hline 26 & M & 58 & Hepatitis $C^{*}$ \\
\hline
\end{tabular}

* Hepatitis C RNA positive. All patients had compensated, Child's Grade A cirrhosis 
Table 2 Psychometric performance and overall status assessed using the $\mathrm{CDR}^{\circledR}$ system in the 26 patients with cirrhosis, free of overt hepatic encephalopathy, undergoing cerebral MRI

\begin{tabular}{|c|c|c|c|c|c|c|c|}
\hline Subject no & PoA & $\operatorname{CoA}$ & $\begin{array}{r}\text { QoEM } \\
(\mathrm{Z}: \\
\end{array}$ & $\begin{array}{l}\text { QoWM } \\
\text { ore)* }\end{array}$ & SoM & Total & 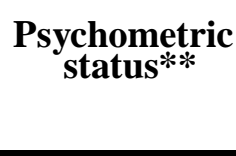 \\
\hline 1 & -1.47 & -3.62 & -2.62 & -1.0 & -14.07 & -22.77 & Impaired \\
\hline 2 & -1.54 & 0.53 & -1.45 & 0.46 & -1.09 & -3.1 & Impaired \\
\hline 3 & -1.21 & 0.9 & -1.31 & 0.79 & -1.9 & -2.72 & Unimpaired \\
\hline 4 & -0.19 & 1.11 & 1.94 & 0.8 & 0.68 & 4.33 & Unimpaired \\
\hline 5 & -6.96 & -1.53 & -2.62 & -1.91 & -2.49 & -15.51 & Impaired \\
\hline 6 & 1.06 & 0.21 & -1.43 & -0.03 & -1.71 & -1.9 & Unimpaired \\
\hline 7 & -1.62 & 1.15 & -0.09 & 0.94 & -2.12 & -1.75 & Unimpaired \\
\hline 8 & -1.82 & 1.15 & -0.52 & 0.17 & -0.54 & -1.55 & Unimpaired \\
\hline 9 & -1.64 & -0.19 & 1.22 & 0.76 & -0.64 & -0.49 & Unimpaired \\
\hline 10 & 0.65 & 0.61 & -0.26 & 0.94 & 0.59 & 2.53 & Unimpaired \\
\hline 11 & 0.59 & -0.15 & -0.49 & 0.37 & 0.33 & 0.65 & Unimpaired \\
\hline 12 & -0.68 & -0.65 & 0.07 & 0.9 & -0.03 & -0.39 & Unimpaired \\
\hline 13 & 0.62 & 0.9 & 1.83 & 0.79 & 0.43 & 4.58 & Unimpaired \\
\hline 14 & 0.86 & -0.49 & -0.29 & -0.03 & 1.21 & 1.27 & Unimpaired \\
\hline 15 & 0.46 & 0.56 & 1.2 & 0.24 & -0.42 & 2.03 & Unimpaired \\
\hline 16 & 0.76 & 0.86 & 0.05 & 1.05 & -1.24 & 1.48 & Unimpaired \\
\hline 17 & -2.26 & -0.91 & 0.33 & 0.8 & -3.60 & -5.63 & Impaired \\
\hline 18 & 0.61 & 0.9 & 0.05 & 0.79 & -2.96 & -0.61 & Unimpaired \\
\hline 19 & -2.46 & -0.92 & -0.58 & -0.94 & -2.89 & -7.78 & Impaired \\
\hline 20 & -0.1 & -6.04 & 0.28 & -1.28 & -0.65 & -7.79 & Impaired \\
\hline 21 & -3.17 & 1.16 & 1.65 & 1.05 & -1.24 & -0.55 & Unimpaired \\
\hline 22 & -0.11 & 0.21 & -2.01 & -0.16 & -1.33 & -3.41 & Impaired \\
\hline 23 & 1.13 & -0.03 & 0.58 & 1.06 & 0.81 & 3.55 & Unimpaired \\
\hline 24 & -2.23 & 0.35 & -0.65 & 0.94 & -4.61 & -6.20 & Impaired \\
\hline 25 & 0.81 & 0.92 & 0.55 & 1.06 & -1.78 & 1.56 & Unimpaired \\
\hline 26 & -2.65 & 0.86 & 0.92 & 0.8 & -2.0 & -2.07 & Unimpaired \\
\hline
\end{tabular}

Abbreviations: $\mathrm{PoA}=$ power of attention, $\mathrm{CoA}=$ continuity of attention, QoEM= quality of episodic memory, QoWM= quality of working memory, SoM= speed of memory

$* \mathrm{Z}$ scores represent the number and direction of standard deviations in the patient data compared to those from the healthy controls

** Psychometric performance was classified as impaired if the total $\mathrm{Z}$ score for all domains was $\leq-3$ 
Table 3 Regional cerebral magnetization transfer ratios (MTR) on MRI in healthy controls and in patients with cirrhosis, by psychometric status

\begin{tabular}{|c|c|c|c|c|c|}
\hline \multirow{3}{*}{ Brain region } & \multicolumn{4}{|c|}{ MTR } & \multirow{3}{*}{$\begin{array}{c}\text { Significance } \\
\text { Controls vs All patients }\end{array}$} \\
\hline & \multirow{2}{*}{$\begin{array}{l}\text { Healthy } \\
\text { controls } \\
(n=15)\end{array}$} & \multicolumn{3}{|c|}{ Patients with cirrhosis } & \\
\hline & & $\begin{array}{l}\text { Total } \\
(\mathrm{n}=24)\end{array}$ & $\begin{array}{c}\text { Unimpaired } \\
\quad(n=16)\end{array}$ & $\begin{array}{l}\text { Impaired } \\
(n=8)\end{array}$ & \\
\hline \multirow{2}{*}{ Frontal white matter } & 57.68 & 55.36 & 55.67 & 54.73 & \multirow{2}{*}{$* * * * * *$} \\
\hline & $(1.28)$ & $(1.61)$ & $(1.5)$ & $(1.75)$ & \\
\hline \multirow{2}{*}{ Caudate } & 48.12 & 46.52 & 46.70 & 46.16 & \multirow{2}{*}{$*$} \\
\hline & $(1.52)$ & (1.39) & $(1.47)$ & $(1.21)$ & \\
\hline \multirow{2}{*}{ Putamen } & 48.48 & 47.04 & 47.20 & 46.72 & \multirow{2}{*}{$* * *$} \\
\hline & $(1.06)$ & $(1.28)$ & $(1.25)$ & $(1.38)$ & \\
\hline \multirow[b]{2}{*}{ Globus pallidus } & 52.79 & 49.71 & 50.11 & 48.93 & \multirow{2}{*}{$* * * * * *$} \\
\hline & $(0.882)$ & (2.93) & $(2.46)$ & (3.77) & \\
\hline \multirow{2}{*}{ Thalamus } & 53.27 & 51.93 & 51.87 & 52.07 & \multirow{2}{*}{ NS } \\
\hline & (1.83) & (1.79) & (1.88) & (1.71) & \\
\hline
\end{tabular}

Data are expressed as mean and standard deviations.

*significance value between healthy controls and the patient entire population with cirrhosis, corrected for multiple comparisons; $* * * * * *=p<0.0001 ; * * *=p<0.005 ; *=p<0.05 ; \mathrm{NS}=$ non-significant. There were no significant differences between the neuropsychometrically unimpaired and the neuropsychometrically impaired patients 
Table 4 Regional cerebral mean apparent diffusion coefficients (ADC) for healthy controls and patients with cirrhosis categorized as impaired or unimpaired by psychometric testing $\left(\mathbf{x 1 0} 0^{-3} \mathrm{~mm}^{2} / \mathrm{s}\right)$.

\begin{tabular}{|c|c|c|c|c|}
\hline \multirow[b]{2}{*}{ Brain region } & \multicolumn{4}{|c|}{ Mean ADC x $10^{-3} \mathrm{~mm}^{2} / \mathrm{s}(\mathrm{SD})$} \\
\hline & $\begin{array}{l}\text { Controls } \\
(n=16)\end{array}$ & $\begin{array}{l}\text { Patients with } \\
\text { cirrhosis } \\
\quad(n=25)\end{array}$ & $\begin{array}{l}\text { Unimpaired } \\
\text { patients } \\
(\mathrm{n}=17)\end{array}$ & $\begin{array}{l}\text { Impaired } \\
\text { patients } \\
\quad(n=8)\end{array}$ \\
\hline \multirow{2}{*}{ Genu of CC } & 0.809 & $0.845^{*}$ & $0.845 \phi$ & 0.848 \\
\hline & $(0.04)$ & $(0.03)$ & $(0.03)$ & $(0.03)$ \\
\hline Splenium of & 0.718 & 0.737 & 0.742 & 0.727 \\
\hline $\mathrm{CC}$ & $(0.03)$ & $(0.04)$ & $(0.05)$ & $(0.03)$ \\
\hline \multirow{2}{*}{ CC body } & 0.769 & $0.816 * * * * *$ & $0.812 \phi \phi \phi \phi$ & 0.824 \\
\hline & $(0.03)$ & $(0.04)$ & $(0.03)$ & $(0.4)$ \\
\hline \multirow{2}{*}{ ACR } & 0.740 & 0.774 & 0.771 & 0.780 \\
\hline & $(0.04)$ & $(0.04)$ & $(0.04)$ & $(0.06)$ \\
\hline \multirow{2}{*}{ PCR } & 0.805 & 0.812 & 0.818 & 0.798 \\
\hline & $(0.04)$ & $(0.05)$ & $(0.05)$ & $(0.03)$ \\
\hline \multirow{2}{*}{ Caudate } & 0.698 & 0.720 & 0.715 & 0.730 \\
\hline & $(0.03)$ & $(0.03)$ & $(0.04)$ & $(0.3)$ \\
\hline \multirow{2}{*}{ Putamen } & 0.683 & 0.707 & 0.704 & $0.712^{\wedge}$ \\
\hline & $(0.02)$ & $(0.04)$ & $(0.05)$ & $(0.04)$ \\
\hline Globus & 0.709 & 0.724 & 0.722 & 0.728 \\
\hline pallidus & $(0.04)$ & $(0.04)$ & $(0.04)$ & $(0.04)$ \\
\hline \multirow{2}{*}{ Thalamus } & 0.721 & 0.734 & 0.732 & 0.741 \\
\hline & $(0.02)$ & $(0.04)$ & $(0.04)$ & $(0.03)$ \\
\hline
\end{tabular}

$\mathrm{CC}=$ corpus callosum; $\mathrm{ACR}=$ anterior corona radiata; $\mathrm{PCR}=$ posterior corona radiata.p values are displayed for the various patient groups where values are significantly different from the healthy controls: patients with cirrhosis $* \mathrm{p}<0.05$; $* * * * * p<0.0005$; neuropsychometrically unimpaired patients: $\phi=p<0.05 ; \phi \phi \phi \phi=p<0.001$; neuropsychometrically impaired patients $\wedge=p<0.05$ 


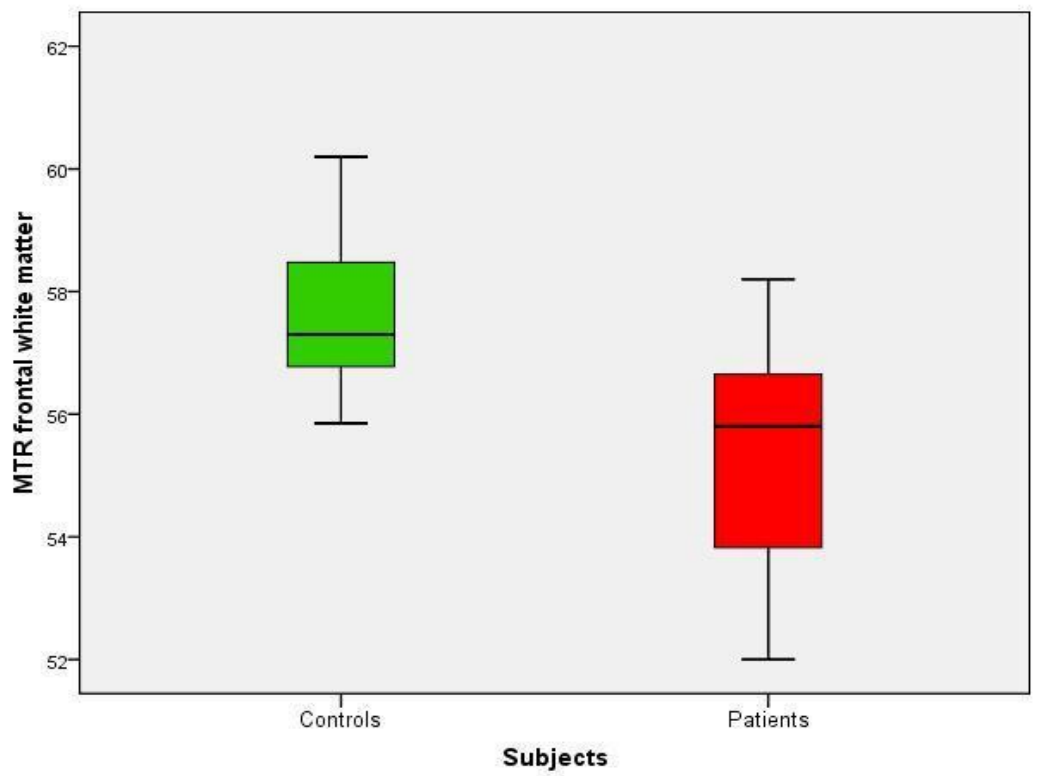

Figure 1 


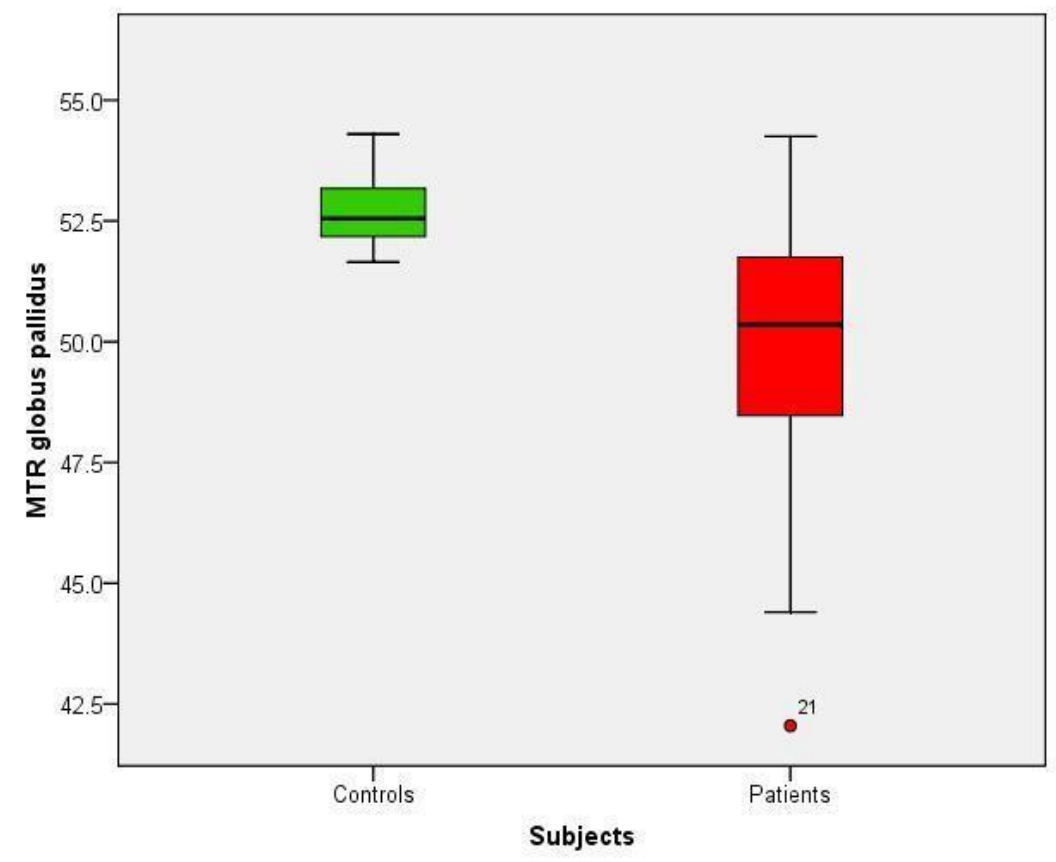

Figure 2 